\title{
Ecological Perspectives of ICT Affordances in Malaysian Higher Education Learning Environment
}

\author{
Magdalina Jamian ${ }^{1}$, Habibah Ab Jalii ${ }^{1}$, Steven Eric Krauss ${ }^{2,1}$ \\ ${ }^{1}$ Faculty of Educational Studies, \\ 2 Institute for Social Science Studies, \\ Universiti Putra Malaysia,Serdang, Selangor 43400, Malaysia \\ habibahjalil@upm.edu.my
}

\begin{abstract}
There is a continuous struggle on understanding learning settings, particularly with ICT integrations (i.e. incorporate the use of ICT in teaching and learning practice and environment). This paper aims to illuminate an alternative means of understanding virtual learning environment which is through affordances (perception-action coupling). Qualitative inquiry implemented in gathering participants' experiences and perceptions regarding ICT integration in teaching practices through focus group discussion and semi-structured interviews. This study shows that preferences of ICT integration in a learning environment closely related to ICT affordances. Understanding of ICT affordances is indispensable in order to assessing conduciveness of learning environments with the ICT integrations.
\end{abstract}

Keywords: Affordances; e-learning; e-learning environment; ICT facilities.

eISSN 2514-751X @ C 2018. The Authors. Published for AMER ABRA cE-Bs by e-International Publishing House, Ltd., UK. This is an open access article under the CC BY-NC-ND license (http://creativecommons.org/licenses/bync-nd/4.0/). Peer-review under responsibility of AMER (Association of Malaysian Environment-Behaviour Researchers), ABRA (Association of Behavioural Researchers on Asians) and cE-Bs (Centre for EnvironmentBehaviour Studies), Faculty of Architecture, Planning \& Surveying, Universiti Teknologi MARA, Malaysia.

DOI: https://doi.org/10.21834/aje-bs.v3i7.260 


\subsection{Introduction}

Learning environments in higher education institutions all over the world are moving towards the integration of information and communication technology (ICT). Such developments are similar to other sectors that are evolving rapidly due to technology integration. In order to fulfill the needs related to technological changes in the learning environment, Ministry of Higher Education are supporting and funding the necessity of ICT integration.

ICT has been the subject of many recent studies in education due to its role as a medium of instruction or educational tool. This function of ICT is a powerful indication of the existence of the technology-education relationship. The development of the technology-education relationship is rapidly evolving and as such, requires much research and discussion. As ICT integration in higher education teaching is a prime concern in blended learning settings, conduciveness ofe-learningenvironmentsareanessential aspect to be explored by the higher education institutions. This paper will, therefore, focus on the conduciveness of e-learning in one higher education teaching and learning environment. It gives a better understanding of the best practices of ICT integration in higher education teaching. In exploring the conduciveness of e-learning in blended learning environments, ICT affordances are the focal point which needs to be understood.

The blended learning approach creating an effective teaching and learning process and curriculum delivery by preparing students to be technologically competent, in order to prepare them for their future work roles. The national goal of developing human capital through knowledge and innovation reached through this approach. The blended learning approach is a combination of traditional face-to-face teaching and learning with online learning. It is wellknown that ICT can enhance teaching and learning strategies to support multiple learning abilities (Kennedy \& McNaught, 1997). A broad range of teaching and learning activities are made possible through ICT by expanding knowledge transfer through an effective delivery system, learning assessment and discussion.

To support educational enhancement through blended learning environments, huge investments in ICT facilities have been made by the higher education institutions. The issue of how the environment is conducive in support students' learning continues to linger, however. Other questions that have yet to be addressed include: how do educational practitioners perceive these facilities; and do educational practitioners find the facilities useful? The conduciveness of e-learning in higher education teaching is subjective. Through assessing the use of ICT, conduciveness of e-learning are possible to be explored.

In the current study, Gibson's theory of affordances was applied to describe the nature of learning environments. 'Affordances' illustrate the relationship between object and actor (human or animal) that enable certain actions. It is a way to explain the actionable properties of a substance as perceived by the user. The concepthas been adapted to explain conduciveness of e-learning in blended learning settings of a Malaysian higher education institution. Conduciveness ofe-learning is considered an actionable property between the world (e-learning environment) and an actor (educational practitioner). User perceptions on ICT facilities or tools in e-learning effect the action of integrating ICT tools and application in e-learning. The importance of this study is to determine how the conduciveness of e-learning affects the 
utilization of ICT tools among university citizens. This can then lead to a better understanding of the conduciveness of the nature of blended learning in Malaysian public universities.

\subsection{Literature Review}

In 1999, Malaysiaimplemented 'the smartschool'and developseducational portals to integrate ICT into primary and secondary schools across the country. Such programs indicated Malaysia's seriousness in making basic ICT integration in primary and secondary schools a reality. Through UNESCO Meta-survey on the Use of Technologies (2001), it is stated that Malaysia had a strategic plan on integrating ICT into the education system. Moreover, there are many efforts have been made to implement best practices of ICT implementation in higher educations' teaching and learning. Facilities in supporting national educational goals are for examples; 'computers, network and Internet, display screen technologies and peripherals, and software and information systems' (Mokhtar et.al, 2007). Additionally, ICT is described in its role as a major support for the educational sector through the implementation of Malaysian Education Development Plan (2001-2010). It is also showing that ICT initiative is implemented in various ways, in Malaysian education.

\section{Affordances}

Affordances is a concept originally coined by a famous ecological psychologist, Gibson (1979). He defined affordances through his observations of relationships between animals and objects in their natural settings, "The affordances of the environment are what it offers the animal, what itprovides or furnishes, either forgood or ill." (p.127). Gibson explains affordances as properties of a substance that offer or enable interactions in the ecosystem that are directly perceived by animals. Norman $(1988,1990)$ and Gaver $(1991)$ both agreed that perceived and perceptible affordances should be identified in affordances' description. However, Strijbos, Kirschner and Martens (2004) added that 'constraint of perceptibility' should be included in this concept. Gaver (1991) proposed that 'constraint of perceptibility' of affordances is a manifestation of hidden affordances. He separated affordances into categories that include: perceptible affordances, correct rejection, hidden affordances, and false affordances. The separation of affordances adapted in this study and shown as follows:

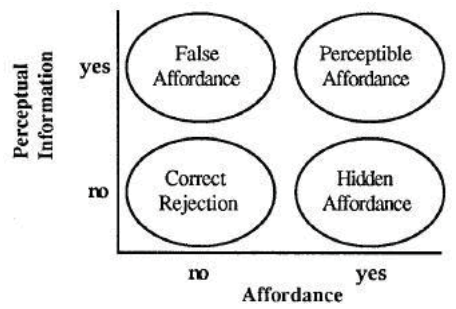

Figure 1: Separating Affordances from the Perceptual Information that Specifies Affordances (adapted from Gaver, 1991) 
In understanding conduciveness of ICT integration, the actual ICT affordance should be understood by accessing perceptible and hidden affordances. It is of note that Gaver's perceptible affordances are substantiated to Gibson's original concept of affordances. Perceived affordances are similar to the original definition. Perceived affordances are what a user perceives of the actual properties of an object that suggest how that object could be used as mentioned by Norman (1988);

"...the term affordance refers to the perceived and actual properties of the thing, primarily those fundamental properties that determine just how the thing could possibly be used. A chair affords ('is for') support and, therefore, affords sitting. A chair can also be carried. (p.9)"

Gaver emphasized that affordances could be obtained even though the user does not receive the right information (i.e. Actionable properties of the object) in the beginning. Both perceptual affordances and hidden affordances are crucial in explaining conduciveness of e-learning and the nature of blended learning environments through ICT affordances.

\section{ICT Affordances}

Affordance as a concept was initially adapted in the context of technological design and on human computer interaction $(\mathrm{HCl})$ by Donald Norman $(1988,1990)$. The concept was also implemented in researching educational tools that enable potential educational activities. Herold's study (2010) on ICT adoption and user choices was closely related to the perceived affordances of ICT in human life. He concluded that ICT should be designed in a way which appropriately fit into human lives.

Research on ICT affordances in computer supported collaborative learning (CSCL) was highlighted in Gaver $(1991 ; 1996)$ and Bower (2008). Other findings indicated that CSCL could promote the advantages of peer- to-peer awareness, exchange, and engagement (e.g. Miyake, 2007). John and Sutherland (2005) also applied the affordances concept in educational practice within pedagogical, technological and ecological aspects.

\subsection{Methodology}

Through ICT affordances that focus on lecturers' teaching experiences, this phenomenological case study are assessing the conduciveness of the learning environment. Participants were lecturers in a Malaysian higher education institution that had experience teaching within a blended learning environment. Participants selected in this study are lecturers that comprising e-learning activities in their teaching. The study explored e-learning teaching activities in order to acquire a better understanding of Malaysian blended learning environments' conduciveness from the perspective of ICT affordances. Through in-depth semi-structured interviews and focus group discussions, e-learning teaching experiences were explored and analyzed using rich description. Data was collected verbatim along the lines of Woolgar (1991) and J. de Winter et al. (2010), who used qualitative inquiry to explore and understand technology integration in education.

In the early stages of data collection, three focus group discussions involving 14 lecturers were conducted. Semi-structured discussion was employed in order to get a better 
understanding of their experience in the ICT teaching and learning process. The questions included how ICT was implemented in their teaching practices and how they perceived ICT in their teaching practices. Secondly, what is the impact of ICT integration in the educational setting, third questions was what could be done to enhance learning with ICT integration, what drives the use ICT in teaching. Final questions were what types of technology are most suitable for their field. The second phase of data collection included three other lecturers to share their experiences ine-learning. The second phase respondents hadadditional criteria that included being members of the university administration. They were involved directly in the institution's policy making that specifically dealt with e-learning affairs.

The sessions were recorded using a digital audio recorder to "ensure that the whole interview is captured and provides complete data for analysis so cues that were missed the first time can be recognized when listing to the recording" (Mathers, Fox \& Hunn, 1998, 2002: 12). Audio data were then transcribed and analyzed by using open coding. Next, emerging themes were systematically managed to answer the research questions. As the data were originally in Malay language, back translations were performed to the data for reliability. The analysis concluded by defining the initial themes and then combining interrelated themes in order to make sense out of the data for the purposes of reporting.

\subsection{Results and Discussion}

The study shows ICT preferences evidenced through participants' expression of ICT affordance. The sense of preferences of ICT integrations in blended learning setting was mentioned in their statements such as ICT 'assist' and 'support teaching'; 'keeping lecture notes organized'; 'to add more colors in teaching processes'; making 'teaching and learning easier'; and 'enhance teaching processes'. Moreover, they perceived that students are familiar with ICT integration in learning activities. Most participants stated that their students preferred to use ICT in learning:

R5: "The fact that the learner nowadays or the student, most of what they get in their daily life is through ICT, they do not read books and poetry anymore. If they read, they will read it online".

R15: 'Students love it when you ask them to go beyond the books'. R15: 'The response is exceptionally good. Most of them, in fact, all of them will do it. Maybe because itis like something of their generation'.

Conversely, these reactions had shown a continuation of actual ICT affordances in Malaysian public university setting that indirectly encouraging the e-learning practice. In the context of affordances, data analysis revealed two categories of 'objects': ICT application and ICT tools. Accordingly, both repeatedly mentions are combinations of perceived affordances and hidden affordances.

\section{ICT as an Educational Tool}

The firstcategory of objects in this study was ICT applications including PowerPoint presentations, social network applications, email, blogs, and learning management systems, which were 
applied in e-learning practices as educational tools. Analysis showed that PowerPoint presentations were the dominant teaching practice among the respondents. Some lecturers are comfortable with the implementation of PowerPoint presentations as a teaching strategy as one participant mentions,

R8: 'if there's PowerPoint, then I felt safe'

However, the effective implementation of PowerPoint in teaching is seen to be quite negative in most cases. One participant pointed out that PowerPoint 'hampered education' and others stressed that PowerPoint decreases scholarly affect in learning. Others felt that interaction with students decreased with the use of PowerPoint.

R3: "PowerPoint, the student do not listen to us, I do not quite like that"

R10: "Everything is provided, and then we put our notes in virtual classes. Student just come for attendance. They do not have any effort to add some notes, sometimes they even do not take the notes out from the bag."

R11: "Concentration student becomes worst, dependability" R9: "PowerPoint had no point..."

R2: "PowerPoint, student just put it there and read, sometimes they do not even point to the existence point. Pointless"

R1: "I do not put everything in my transparency same with PowerPoint...what I do not understand, they listen more with my transparency"

R3: "When we give notes, they will have the tendency to follow our notes."

These responses highlighting how respondents perceived drawbacks of PowerPoint in their teaching practice. They thus expose the hidden affordances of PowerPoint. One respondent, however, admitted that the problem lies in the way ICT applications such as PowerPoint are used in educational practice:

R5: "When people use PowerPoint, they do not use it as the way PowerPoint designed to be used, there is competition between us and the PowerPoint. There's a lot of stuff in the slides."

At the time of the study, other than PowerPoint, a uniform learning management system had been recently introduced. This learning management system (LMS) was designed as a supportive educational tool with many capabilities. Problems with the LMS mentioned by the respondents include many technical difficulties in utilizing the system and an unfriendly interface. Others ignored the LMS altogether due to their frustration and despair from previous attempts of trying to integrate the LMS into their teaching. Lastly, some mentioned accessibility issues brought up by students:

R3: "In ICT usage, I put LMS at the lowest ranking, for me LMS not helping much. Student complained with its accessibility. Because of these problems, I use more email for communication. It is faster. "

Interestingly, some participants explored LMS through ICT affordances, sharing their experiences through trial and error and trying nearly all of the relevant features of the system. Although trainings were provided by the university, they made it clear that they needed to explore 
LMS on their own. The effort of exploring LMS features shows that they are indirectly transferring hidden affordances into the perceived affordances. The transformation of affordances happened when they selectively use certain features of LMS after some attempt. At the time of the study, LMS was still in development and undergoing continuous upgrading; despite this, system had many features that are to enhance teaching and learning practices. However, a lot more features were not mentioned by the respondents. In addition, the use of online journals, blogs, email and social networks also emerged in this study as useful tools for teaching. Facebook was mentioned several times as not only a communication alternative, but as an educational tool, as well.

R15: "Facebook is part of it. In my cases, for example, I also give them the meaning of words, and all those things that related to language." R4: "ICT ease communication process between student and lecturer. It does not matter what application is used, even using Facebook."

Participants also have their own blogs while some shared academic content and issues. These applications had support in terms of knowledge sharing, communication processes, and, perhaps most importantly, on knowledge acquisition. This is an evidence of perceived affordances for blogging activities.

\section{ICT as an Educational Medium}

The second analysis is on the medium which consists of ICT tools such as handheld gadgets, ICT hardware, and Internet connections and are also considered educational media. These tools were also discussed under data collection processes. Although not widely discussed in the context of datacollection processes, they play a prominentrole in educational practice. The function differs according to the learning objectives.

The internet is a tool that is extremely significant as an educational medium. With the Internet, interactivity in the learning process plays a crucial role as mentioned by respondents:

R7: "The use of the internet, my student mostly use internet, especially in writing an essay"

R15: "Self directed learning, they (the student) have to go online to do the exercises."

R7: "Go to online and, for example, check on the pronunciations" R15: "They can relate to it and then its interactive... They get the answer and then they like it that they know immediately when they are wrong."

Real-time communication through internet attracts users especially among students in their learning activities. In addition, the majority of users were able to perceive the information of ICT tools as an educational medium. This explains perceived affordances of ICT tools as educational mediums. ICT tool's actionable properties perceived by users reflect their actions in ICT integration in learning practices.

\section{Transforming Affordances}

Negative hidden affordances could be transformed into the perceived affordances, and such transformation could be developed. In the context of this study, for example, a participant claims s/he once neglected to use LMS in the beginning. After attending training, s/he made 
an effort to explore him/herself of the system. Only then, s/he realized the LMS's functions in his/her teaching. Such case evidenced in this study explained how through self-exploration of the LMS features give a better understanding of LMS integration in teaching practices. Negative hidden affordances, therefore, could be changed if appropriate strategies are planned by the organization. Through workshop, for example, or encouragement for selfexploration among the lecturers could change their perspectives of ICT affordances.

\subsection{Conclusion}

ICT tools were mostly perceived by participants as educational media, which create perceivable affordances that lead users to the best practices of use of those tools. Hidden affordances occurred in several ICT applications, especially in LMS and PowerPoint presentations. In order to transfer hidden affordance to perceived affordances, education and training should be conducted to expose users to best practices of ICT in e-learning. This might help to transfer hidden affordances into the perceived affordances to achieve environmental conduciveness in order to enhance e-learning in Malaysian public universities. As e-learning settings continue to progress and develop, educational practitioners should perceive them as educational tools without ignoring the numerous features they offer.

\section{Acknowledgement}

Special thanks to Research University Grant UPM that funded this study.

\section{References}

Ministry of Education, Malaysia, (2003). Educational Development Plan for Malaysia 2001-2010. Kuala Lumpur: Ministry of Education. Available online at: http://planipolis.iiep.unesco.org/upload/Malaysia/ Malaysia\%20Education\%20development\%20plan\%202001-2010\%20 summary.pdf.

Gaver, W.W. (1991). Technology affordances. Proceedings of the Conference on the CHI 91Human Factors in Computing Systmes Conference, ACM, p.79-84.

Gibson, J. J. (1977). The Theory of Affordances. In R. E. Shaw \& J. Bransford (Eds.), Perceiving, Acting, and Knowing. Hillsdale, NJ: Lawrence Erlbaum Associates.

Gibson,J.J.(1979). TheEcologicalApproachto VisualPerception.Boston: Houghton Mifflin.

Kennedy, D. \& McNaught, C. (1997). Design Elements for Interactive Multimedia.AustralianJournalofEducational Technology, 13(1),1-22

Mathers, N., Fox, N., Hunn, A. (1998). Trent Focus for Research and Development in Primary Heath Care: Using Interview in a Research Project. Sheffield: Trent Focus Group.

Miyake, N. (2007). Computer Supported Collaborative Learning. In R. Andrew and C. Haythornthwaite (Eds.), The SAGE Handbook of E-Learning Research. London: SAGE Publications Ltd. 
Mokhtar, S., Alias R., Rahman A., (2007). Rubric for Assessing ICT Infrastructure in Malaysia Higher Education. Available online at:http:// eprinzzts.utm.my/3292/3/Shamsul_Anuar_Mokhtar_(After_Review)_PARS_06-edited.pdf, last viewed August 2011.

National Philosophy of Education, Retrieved date: $1^{\text {st }}$ August 2011. From, http://jpt.mohe.gov.my/index.php

Norman, D. A. (1988). The Psychology of Everyday Things. New York: Basic Books.

Norman, D. A. (1990). The Design of Everyday Things. New York: Doubleday.

Strijbos, J. W., Kirschner, P. A., \& Martens, R. L. (2004). (Eds.) What We Know about CSCL: And Implementing it in HigherEducation. Boston, MA: Kluwer Academic/Springer Verlag.

Tenth Malaysia Plan 2011-2015 (n.d.) Retrieved date: $1^{\text {st }}$ August 2011.

From: http://www.nitc.my/

UNESCO (2001), Meta-survey on the Use of Technologies in Education in Asia and the Pacißc. Paris: UNESCO. 